\title{
Filipino Practicum Students' Close Encounter with Asian Tourists: An Experiential Study
}

\author{
Emily Jill T. Nival ${ }^{1}$ and Candice P. Aguilos ${ }^{2}$ \\ 1 Leyte Normal University, Tacloban City and ej.nival@lnu.edu.ph \\ 2 Leyte Normal University, Tacloban City and jo_7270@yahoo.com
}

\begin{abstract}
Practicum students play a major part in the hospitality industry. They support the regular staff assigned in the different sections in hotels, restaurants, travel agencies, airports and other tourism establishments all over the world. For Filipino hospitality and tourism practicum students they have their share of face to face encounters with Asian tourists. It is expected that their initial exposure to foreign tourists are with guests from the neighbouring countries This qualitative study was conducted to identify what were the challenges, lessons and wisdom that they have learned after they were exposed to tourists coming from Korea, Japan, and Thailand. Narrative journals submitted by students after their off-campus and in campus practicum were thoroughly analysed .Major findings which emerged from the study are (1) Students have a difficulty of communicating with Asian Tourists because of language barrier (2) Asian tourists are reserved but easy to please guests (3) Coping with multi-cultural diversity is a major challenge among students in providing guest services. (4) Despite of challenges met, students are happy dealing with Asian tourists. They strongly recommend to school authorities to offer courses such as Asian languages and Asian Culture and Traditions to improve the curriculum of hospitality and management programs. It is also recommended to invite visiting professors to teach these recommended courses. Through this their level of confidence in dealing with tourists all over the Asian region will be improved.
\end{abstract}

\section{Key Words. Asian Tourists, practicum students, experiential, Filipino}

\section{INTRODUCTION}

Practicum as a form of experiential learning usually is a course or student exercise involving practical experience in a work setting (whether paid or unpaid) as well as theoretical study, including supervised experience as part of professional pre-service education (Moore, 2010). In the case of Bachelor of Science in Tourism, Hotel and Restaurant (BSTHRM) and Bachelor of Science in Hotel and Restaurant Management (BSHRM) students of Leyte Normal University, practicum is comprised of two areas: In-campus practicum in LNU House and Off-campus practicum in hotel establishments within the country or abroad.

These students when deployed in the different practicum assignments serve clients and interact with guests of the establishments they are assigned to just like regular employees. With the downsizing of hotel companies in the 1980s and 1990s, internships became a way of supplementing staff during peak seasons and auditioning students for full-time positions upon graduation (Breiter, Cargill, \& FriedKline, 1995). However, the students deployed in practicum no longer just supplement staff during peak periods but complement existing hotel staff even in regular operations.

The internship is one of the most effective models of experiential learning in hospitality education. However, to be successful, it requires the cooperation of students, employers, and educators (Yiu \& Law, 2012). Internship or Practicum is a requirement for students to graduate in a BSHRM and BSTHRM degrees in various schools and universities offering hospitality education. 
Hospitality higher education traditionally seems to focus more on disseminating knowledge and conducting research. There are criticisms on undergraduate students who have little understanding on how to apply the knowledge learnt from classrooms and what practical skills to obtain upon graduation (Yan \& Cheung, 2012). These practical skills are acquired by students while having handson experiences and training in a real world set-up, thereby complementing what they have learned in theory inside the classroom.

This study is anchored on Kolb's Experiential Learning Theory (ELT). ELT is an adult learning theory that highlights the critical role experience plays in affecting learning and change $(\mathrm{Ng}$, Van Dyne \& Ang, 2009). Lashley \& Barron (2006) suggest one way of approaching the learning needs of these students is to use Kolb's experiential learning cycle as a way of encouraging the development of 'balanced' learning strategies that lead to reflective practice.

Many hospitality curricula incorporate some form of industry-based experiential learning to complement the classroom environment (Lee, 2008). The study of Lee (2008) confirmed many of these previously documented benefits of experiential learning and identified new learning outcomes or benefits for students who participate in experiential learning, such as an increased understanding of how organizations function, increased ability to view career expectations realistically, an increased network of professional contacts, increased ability to take initiative, increased ability to adapt to change, increased leadership skills, and increased financial management skills.

Meanwhile, the tourist industry in the Association of South East Asian Nations (ASEAN) region has grown at an unprecedented rate, keenly reflecting the rapid growth of the individual economies of the region (Sadi, \& Bartels, 1999). With improving economic conditions, citizens of these countries travelled more. Since the main market of tourism in the Philippines come from the neighbouring countries in Asia, most of the interaction with foreign guests of the students are from these nations.

There has been an increase in the popularity of among Filipino hospitality students to have their internship or practicum abroad in order to widen their experience in handling international guests and gain an edge over those students having their internship locally. According to the study of Van Hoof (2000), students who work abroad as interns are better prepared than their non-participating peers to face some of the challenges they will encounter in the increasingly globalized hospitality industry of tomorrow. Students who study abroad may have greater intercultural proficiency, increased openness to cultural diversity, and become more globally minded than those students remaining in a traditional campus setting (Clark, Flaherty, Wright, \& McMillen, 2009).

However, international practicum is not the only way to interact with foreign guests. This is also possible in local practicum venues because there is a continued increase in intraregional travel among Asia-Pacific residents because of continued economic growth and the willingness of governments to open their countries to foreigners and to allow their own nationals to travel freely abroad (Mak \& White, 1992).

This study examined the challenges encountered by practicum students in dealing with Asian tourists while having their practicum locally or abroad. A content analysis of the Practicum Reports submitted by the BSHRM and BSTHRM students and interviews were conducted in order to know the problems they encountered in their interactions with Koreans, Japanese and Chinese guests in the course of their practicum duty.

\section{METHOD}

\section{Participants}

After completing all academic subjects for three years, students taking the courses BSTHRM and BSHRM are required for an on-the-job training (OJT). It is important to note that these practicum did not only experience international training but localas well. This training is divided into three semesters to which BSTHRM starts on a summer since it includes Travel Management, Hotel and 
Restaurant Practicum while BSHRM are required only for Hotel and Restaurant practicum. It is a requisite which is essential that they submit a narrative report for their experiences specifically on their encounters with Asian tourists.

Through the report of the students it was found out that there were some challenges/issues that surfaced. It cannot be avoided that there may be some biases on how students deal with some Asian tourist as it could be an indication that they could be conceived as poor in deciphering what the tourist wants from them and on the part of the tourist more effort in sending the message so they could just be understood. Few from these trainees volunteered to be interviewed and it was further validated that it was really a difficult experience on their part. Since it is now practiced that practicum has to be open with their concerns to their adviser it became easy to share their experiences.

For ethical considerations, we have maintained anonymity for both the respondents and Asian tourists collectively.

\section{Procedure}

This paper has used the content analysis method for this qualitative study. Content analysis does not proceed in a linear fashion and is more complex and difficult than quantitative analysis because it is less standardized and formulaic (Polit \& Beck, 2004). There are no simple guidelines for data analysis: each inquiry is distinctive, and the results depend on the skills, insights, analytic abilities and style of the investigator (Hoskins \& Mariano, 2004). One challenge of content analysis is the fact that it is very flexible and there is no simple, 'right' way of doing it. Researchers must judge what variations are most appropriate for their particular problems (Weber, 1990), and this makes the analysis process most challenging and interesting. An enormous amount of work is required during the process (Polit \& Beck, 2004).

Respondents' narrative report were collected after completion of the required number of hours. A random interview was conducted apart from the report which were submitted for them to relate their encounters with Asian tourists. These were all documented for analysis of the texts. According to Clandinin and Connelly (1994), the current methodological preference is towards studying texts rather than using interviews. It is assumed that meaning is contained in narrative texts and the study of texts is therefore primary focus of educational studies.

One possible pitfall that can occur during data collection and transcription is transcription errors inaccurate punctuation; mistyped words that change the entire meaning of what was actually said, or missing or misinterpreted words (Easton, McComish \& Greenberg, 2000). So in order to minimize these pitfalls the researcher personally transcribed the narrative texts.

\section{FINDINGS AND DISCUSSION}

Four general themes emerged from the analysis of the narrative reports submitted by the students and from the interviews conducted.

\section{LANGUAGE BARRIER}

The respondents found it difficult to communicate with Asian guests because of language barriers. They were having a hard time understanding what the guests were trying to say. Similarly, Asian guests found it difficult to express themselves and to comprehend the information that the respondents were trying to relay to them. Despite using simple English words, the Asian guest seemed not to understand it very well. This often led to miscommunication between guests and respondents.

Significant Response 1: "I encountered an Asian guest who wanted to transfer to another table but it is already taken. I explained to her but it seemed that she can 't understand English." 
Significant Response 2: "Most of the Asians were having a hard time understanding the English language. Good thing, hand gestures helps a lot during conversations and explanations."

Significant Response 3: "It is hard for them to speak in English, so for us to understand each other we use sign language or hand signals."

Significant Response 4: "I have encountered problems such as miscommunication with the guests, because some of them do not listen well with what the associates (OJT) would say."

Significant Response 5: "Most Asians do not understand English so you have to make an effort in talking to them because there are some words that they don't understand."

Significant Response 6: "Asian guests cannot understand fast talk, you need descriptive word by word talk so that they can understand me."

\section{DIFFERENCES IN CULTURAL ATTRIBUTES AMONG ASIAN GUESTS}

The respondents reported that Asian tourists were in general generous when it comes to showing their appreciation of the efforts given by the hospitality service providers. They also noted that although other Asians were respectful, kind, disciplined and polite, there were also those who appeared demanding, noisy and aggressive.

Significant Response 7: "They are generous in giving tips and fruits."

Significant Response 8: "Common characteristic among Asian guests is that they are extremely respectful."

Significant Response 9: "They are friendly and affable. Most of them are well disciplined."

Significant Response 10: "Asian people are naturally neat and kind persons."

Significant Response 11: "I have found out that Asian guests does not want to sit near the other Asian guests because according to them, they are noisy and aggressive even when simply just talking."

Significant Response 12: "During my duty as egg station cook/attendant, there were Asian guests who were very demanding but they can't express and suggest what they want because it is hard for them to speak in English..."

\section{COPING WITH MULTI-CULTURAL DIVERSITY}

The respondents came up with varied ways in order deal with diverse culture of Asian guests. With differences in language, they adapted by learning basic words and using hand signals and gestures in order to get their message across. The respondents also practiced guests' relations skills and developed patience in dealing with Asian guests. They also increased their cultural awareness by understanding the cultural differences among the guests they served. The respondents recognized the benefit of an Asian language course in the university, specifically Japanese, which helped made their interaction with these Asian tourists easier. Having a strong presence of mind was also important.

Significant Response 13: "My job was to greet guests and lead them to their tables. I have even learned some Korean words."

Significant Response 14: "I adapted with Asian guests with the use of hand signals/language when talking to them."

Significant Response 15: "Luckily, Ian helped me explain by using hand gestures. He advised me to simplify my English and use gestures." 
Significant Response 16: "The training has helped me a lot in giving such a long patience towards guests like the times when guests insists that they want even though you already explained to them politely and clearly."

Significant Response 17: "I would like to practice my guest relation skills."

Significant Response 18: "Cultural awareness is important and you'll need to interact with people from other cultures."

Significant Response 19: "Being understanding of the different cultures and behaviours is important in this industry."

Significant Response 20: "I was able to cope up with language barrier by continuously talking to them, asking them to teach you their language an in exchange teach them English, then learn body language and always have presence of mind."

Significant Response 21: "With the arrivals of the Asian guests, my knowledge in Nihongo was put to use, as sometimes we converse in Nihongo. I was glad we had Nihongo subject back in my second year."

Significant Response 22: “... luckily I remembered the Japanese term for no, which is "ie" that I learned from school and finally they understand me."

Significant Response 23: "Japanese was quite easy for me to handle since I have a background knowledge of Nihongo."

\section{VIEWS ON THE INTERACTIONS WITH ASIAN TOURISTS}

The respondents saw the experiences they had in interacting with Asian guests as an opportunity for them to understand the different cultures in Asia. They viewed it as a way to broaden their perspectives and better prepare them for the global world of hospitality. It also opened their minds on how to avoid the misunderstandings brought about by these differences. Despite the problems and difficulties they have encountered with Asian guests, the respondents were pleased to have been given the opportunity to deal with these tourists.

Significant Response 24: “... my experience in dealing with Asian guests included some of their customary way of living and how the general citizens of these Asian populace see us (Filipinos)."

Significant Response 25: "Whenever they are in conversation with me, I am often drawn to their accentuated facial expression and consistent nodding..."

Significant Response 26: "In order to lessen the problem about language barriers, students who are about to go render duty should be taught about basic words so that it would be easier for them to communicate with locals and foreign nationalities."

Significant Response 27: "Before, I never knew how hard it was to work with other people from and to deal with different races until I finished my training. Nothing is easy or hard, it's just a matter of balancing things and handling it in the right way."

Significant Response 28: "I became more respectful for I know everything you do whether small or big it has an impact to others."

Significant Response 29: "Keeping an open mind can help to avoid any misunderstanding that occurs between beliefs and values representing a person's culture." 
Significant Response 30: "Getting to know people and gaining friendship with people in different language, culture and religion was a different feeling for me."

\section{CONCLUSION AND SUGGESTION}

When practicum students are deployed to their respective establishment, there are a lot of commonalities with regards to their experiences. Because we come from diverse culture it is already expected that experiences may be positive or negative.

Language barrier and coping with multi-cultural diversity are some challenges that were mostly encountered by practicum students with Asian tourists during their on-the-job training whether its local or international internship. It was difficult at first since they have to adjust in their new environment and with their encounter with Asian tourists.

On the other hand, they were also able to have a good experience with selected Asian tourists where it was gratifying on their end whenever they are given tips whether in the form of money or in kind. According to them there were Asian tourists who are reserved and easy to please. Filipino hospitality is innate in everyone so as much as possible practicum students will do their utmost resource to be of service to any tourists and to please them in any way.

Recommendations

Since this is a qualitative study, findings maybe useful in many ways. First, recommendations will be beneficial to Asian tourists, to the practicum, to the faculty members teaching the course and to the university in improving the curriculum. Second, school officials are strongly encouraged to offer courses such as Asian Languages, and Asian Culture and Traditions. Third, upon offering these courses this could be one way where the curriculum for hospitality and management programs may also be improved. Fourth, inviting visiting professors to teach the recommended courses may also be done. Fifth, the level of confidence and self-esteem in dealing with tourists all over the Asian region will be improved. And lastly, more or less Asian tourists will now find it easy to deal with Filipino practicum and rapport may be established.

\section{REFERENCES}

Birkbeck, J., \& Shawna Bava, B. S. W. (2007). E-Supervision of an International Practicum: From Tsunami Relief to the Ladies of the Club Reflections: Narratives of Professional Helping, 13(4), 1-14.

Breiter, D., Cargill, C., \& Fried-Kline, S. (1995). An industry view of experiential learning. Hospitality Review, 13(1), 8.

Buchanan, J. (2004). The Thais That Bind: The Contribution of an International Practicum to Students' Intercultural Understanding. Pacific-Asian Education Journal, 16(2).

Charlotte Pietersen. (June, 2002) Research as a Learning Experience: A Phenomenological Explication

Cimacio, M. B. C., Nullar, M. B., \& Reside, O. H. FRONT OFFICE OF ACCREDITED HOTELS IN BAGUIO CITY: PROFILE, PROBLEMS AND STRATEGIES FOR QUALITY SERVICE.

Clark, I., Flaherty, T. B., Wright, N. D., \& McMillen, R. M. (2009). Student intercultural proficiency from study abroad programs. Journal of Marketing Education.

Deel, G. L. (2010). Exploring the Association of the Attributes of Self-service Kiosks, Customer Check-in Satisfaction, and Customer Commitment in Convention Hotels: The Case of the Rosen 
Centre Hotel, a Convention Hotel (Doctoral dissertation, University of Central Florida Orlando, Florida).

Duffy, A. (2012). Out of Their Comfort Zone Student Reactions to Cultural Challenges While Travel Writing. Asia Pacific Media Educator, 22(1), 1-13.

Erb, M. (2000). Understanding tourists: interpretations from Indonesia.Annals of Tourism Research, 27(3), 709-736.

\section{Hartwood \& Garry (2003). The Qualitative Content Analysis Process}

Johnson, J. P. (2004). Experiential learning in emerging markets: Leveraging the foreign experience. In Business education and emerging market economies (pp. 235-249). Springer US.

Lashley, C., \& Barron, P. (2006). The learning style preferences of hospitality and tourism students: Observations from an international and cross-cultural study. International Journal of Hospitality Management, 25(4), 552-569.

Lee, S. A. (2008). Increasing student learning: A comparison of students' perceptions of learning in the classroom environment and their industry-based experiential learning assignments. Journal of Teaching in Travel \& Tourism, 7(4), 37-54.

Mak, J., \& White, K. (1992). Comparative tourism development in Asia and the Pacific. Journal of Travel Research, 31(1), 14-23.

Moore, D. T. (2010). Forms and issues in experiential learning. New Directions for Teaching and Learning, 2010(124), 3-13.

NENIN, M., SALEHUDDIN, M., ZAHARI, M., RADZI, S. M., OTHMAN, Z., \& AMRAN, M. (2010). Assessing Guests' Views of Service Delivery Attributes at Captive Hotels.

Ng, K. Y., Van Dyne, L., \& Ang, S. (2009). From experience to experiential learning: Cultural intelligence as a learning capability for global leader development. Academy of Management Learning \& Education, 8(4), 511-526.

Reisinger, Y., \& Turner, L. (1998). Asian and western cultural differences: the new challenge for tourism marketplaces. Journal of international hospitality, leisure \& tourism management, 1(3), 2135 .

Sadi, M. A., \& Bartels, F. L. (1999). Recent developments in The Association of South East Asian Nations (ASEAN) tourist industry: manpower development, training issues and competitiveness. Competitiveness Review: An International Business Journal, 9(1), 19-29.

Van Hoof, H. B. (2000). The international internship as part of the hospitality management curriculum: Combining work experience with international exposure. Journal of Hospitality \& Tourism Education, 12(1), 6-15.

Yan, H., \& Cheung, C. (2012). What types of experiential learning activities can engage hospitality students in China? Journal of Hospitality \& Tourism Education, 24(2-3), 21-27.

Yiu, M., \& Law, R. (2012). A review of hospitality internship: Different perspectives of students, employers, and educators. Journal of teaching in Travel \& Tourism, 12(4), 377-402. 